\title{
The Effectiveness of Low-Investment Pachinko/Pachislot in Reducing Gambling-Related Harms: A Cross Sectional Study
}

\author{
Kengo Yokomitsu ( $\sim$ yokomitsuken5@gmail.com ) \\ Kawasaki University of Medical Welfare https://orcid.org/0000-0002-3242-7776 \\ Kazuya Inoue \\ Waseda University
}

Tomonari Irie

Hokusho University

\section{Research Article}

Keywords: problem gambling, harm reduction, low-investment pachinko

Posted Date: July 9th, 2021

DOI: https://doi.org/10.21203/rs.3.rs-457485/v2

License: (1) (i) This work is licensed under a Creative Commons Attribution 4.0 International License.

Read Full License 


\section{Abstract}

\section{Background}

Pachinko and pachislot are popular types of gambling activities in Japan. Prior studies in Japan have reported a concerning prevalence of problem gambling among adult players. While these studies have identified various gambling-related harms, Japanese research on harm-minimization strategies is scarce. Therefore, the present study aimed to analyze the effectiveness of low-investment pachinko and pachislot as a harm-reduction strategy.

Methods

We considered gamblers who played games that cost the typical amount of money to be "normal-pachi players." Those who played low-investment games were categorized as "half-pachi players" and "quarterpachi players," reflecting those who played games at half or one quarter the cost of a typical machine, respectively. To assess the harm-reduction effect, a one-way ANCOVA was conducted to compare the impact of the groups (normal-pachi players [ $n=101]$, half-pachi players [ $n=104]$, and quarter-pachi players $[n=100]$ ) on dependent variables, namely the number of days players had gambled during the prior month; total time and amount of money spent on gambling; debts caused by gambling; gambling severity; cognitive distortion; depressive symptoms; and problems in work, family, and social life.

Results

We demonstrated that the amount of money spent by quarter-pachi players on gambling during the past month was lower than that of normal-pachi players. However, we did not find significant differences with respect to any other gambling-related harms among normal-, half-, and quarter-pachi players.

\section{Conclusion}

Low-investment pachinko and pachislot can reduce the amount of money spent on gambling. It can thus partly act as a harm-minimization strategy. Moreover, the results of the present study indicate that the problems at work affect various outcomes for gamblers. Given that $90 \%$ of the participants in this study were employed, the results of this study may have important implications for employed gamblers.

\section{Background}

Problem gambling can have considerable negative impact on people's lives [1]. Reportedly, the worldwide rates of lifetime problem gambling fall between 0.7 and $6.5 \%$ [2]. In Japan, a nationwide prevalence study revealed that approximately $1.5 \%$ of participants were classified as likely problem gamblers [3]. One of the essential characteristics of gambling in Japan is the type of gambling available. In Yokomitsu et al.'s [4] study, pachinko and slot machines (called pachislot in Japan) were the most common types of gambling activities engaged in by university students. In addition, Shoun et al. conducted a questionnaire study on 5,060 Japanese adults aged 18-79 years using a low-coverage error sampling method and 
found that $11.5 \%$ of participants $(n=582)$ had played pachinko or pachislot in the past 12 months [5]. Furthermore, the 9,000 slot machines and pachinko gambling venues in Japan make gambling highly accessible.

Pachislot, a popular type of gambling in Japan, is similar to casino slot machines that use cash. In Japan, players play pachislots using medals which also called tokens, which can be exchanged for cash. An important difference between pachislots in Japan and slot machines in overseas casinos is that the former is a player-participation type of gambling that requires the player to pull a lever on the side of the machine, push three buttons to stop a rolling reel, and align various symbols. A set of these processes is a game (play) in a pachislot. Players have the chance to win a large prize (nearly a jackpot) with a fixed probability for each game. Although this probability varies according to the type of pachislot, a one-in-two hundred chance is frequently applied. In each game, an animation with lights, sounds, and images is generated on a 14-inch $(35.6 \mathrm{~cm})$ liquid crystal display on the top of the reel. Large and loud animations signal a high probability of a big win. These animations include video gaming, which can immerse players in the gambling.

In contrast, pachinko, which is also popular in Japan, resembles a vertical pinball machine. A pachinko machine uses numerous pachinko balls, each approximately $1 \mathrm{~cm}$ in diameter. When a ball enters a catcher near the bottom center of the playing board, a big win is generated with a fixed probability. Similar to pachislot, the probability varies according to the kind of pachinko; however, a one-in-300 chance is frequently applied. The animations, with images, sound, and light production, in pachinko are the same as in pachislot wherein a large and loud production is associated with a high probability of a big win. However, in both pachislot and pachinko, gamblers sometimes do not achieve a big win, despite a pompous production. Such an event is called a near-miss event.

Problem gambling can lead to a variety of harms. In Langham et al.'s [6] review, gambling-related harm is defined as "any initial or exacerbated adverse consequence due to an engagement with gambling that leads to decrement to the health or well-being of an individual, family unit, community or population." This review identified harms that could occur either sequentially or simultaneously. These types of harm include financial, interpersonal, emotional or psychological, health-related, professional, educational, and criminal harms. To reduce these harms, international guidelines recommend implementing evidencebased and best practice policies to minimize gambling, including specific requirements for policies on internet gambling. These guidelines include a minimum legal age of 18 years for gambling participation, licensing of gambling venues and activities with responsible gambling, and mandated consumer protection strategies. Additionally, brief interventions should be available for those susceptible to or facing gambling-related harm. Several harm-minimization strategies have been devised to prevent pathological gambling behaviors and facilitate self-control with respect to gambling [7]. These strategies include supply-reduction (reducing opportunities for gambling and providing low-investment gambling machines), demand-reduction (education to raise awareness about the potential harms of serious gambling), and harm-reduction interventions (approaches to reduce gambling-related harm, such as personalized normative feedback) $[8,9]$. 
Although studies on approaches and policies to minimize gambling-related harm have been conducted, research related to harm reduction is still nascent in Japan. For example, some of the harm-minimization strategies and policies currently in place in Japan include pre-commitment/limits on the purchase of online horse race tickets upon application by an individual or a family member, removal of ATMs from horse, bicycle, and boat race tracks, setting limits on ATM withdrawals at pachinko venues (e.g., maximum $\backslash 30,000$ per day), and self-exclusion from pachinko venues on behalf of the applicant or a family member. In an earlier study conducted overseas [10], slot machines with a maximum stake of \$1 (a low-investment gambling machine) were reported to reduce playing time, financial loss, and consumption of alcohol and cigarettes while gambling. This suggests that this type of low-investment gambling could also lead to harm reduction in Japan. Low-investment gambling in Japan is known as quarter-pachinko/pachislot (called ichi-yen pachinko/go-yen pachislots in Japan) and halfpachinko/pachislot (called ni-yen pachinko/ ju-yen pachislots in Japan). Quarter-pachinko/ pachislot is gambling at one-quarter the cost of regular pachinko/pachislot, while half-pachinko/pachislots is gambling at one-half the cost of regular pachinko/pachislot.

In the present study, we defined low-investment pachinko and pachislot as playing pachinko and pachislot for half or one quarter of the normal cost. Gamblers who played pachinko/pachislot for half of the normal cost were called "half-pachi players," and those who played for a quarter of the normal cost were called "quarter-pachi players." We categorized gamblers who played for the normal amount money as "normal-pachi players." Notably, when gamblers play low-investment pachinko and pachislot, they are able to play twice or even four times as long as normal pachinko and pachislot for the same amount of money. Additionally, as gamblers bet less in this type of gambling, they are only able to gain half or a quarter of the normal amount. Thus, low-investment pachinko/pachislot could be considered low-risk and low-return gambling. Based on previous studies [20], low-investment pachinko gamblers could face lessimpactful versions of several of the harms faced by normal gamblers, including gambling-related behaviors such as playing time and loss. However, it is unclear whether quarter- pachinko/pachislot and half- pachinko/pachislot would be effective in reducing gambling-related harms.

Therefore, we aimed to explore the effect of these low-investment types of pachinko/pachislot on gambling-related harms in adult gamblers in Japan. Specifically, we sought to compare gambling-related harms among normal-, half-, and quarter-pachi players. In the present study, we considered the following to be gambling related harms: player debt; the number of days players had gambled during the previous month; the total time and money spent on gambling; the severity of gambling; gambling cognitive distortion; depressive symptoms; and the degree of disability at work, home, and in players' social lives. We hypothesized that half-, and quarter-pachi players would be less all gambling related harms than normal-pachi player.

\section{Method}

\section{Participants}


In all, 305 Japanese gamblers (males $=261$, females $=44$, mean age $=51.1$, SD $=12.9$ ) aged 20 years and older were recruited from September 11-12, 2019 through the online survey panels of a major Japanese Internet survey company (Rakuten Research Inc., Tokyo, Japan). None of the data from these participants had missing values.

\section{Procedure}

A website was created for this online study. Participants who registered with the internet survey panels were recruited to participate in an online study presented as "Behavior and cognition about gambling in daily life." Before participation, every potential participant was given information on the study through a separate screen to ensure and obtain informed consent for study participation. This explanation emphasized that participation was entirely voluntary. Completion of the Internet survey was regarded as consent to participate in the study, as the online survey was anonymous. In this study, the respondents were asked to select which of three types of pachinko (normal-, half-, and quarter-pachinko/pachislot) they played most, and then they were invited to answer a series of questionnaires.

\section{Measures}

Demographics. Participants were asked questions on gender, age, education level, annual income, allowance which refers to money spent on entertainment and leisure, and marital status.

Gambling behavior, gambling history, and debts caused by gambling. Participants were asked to report the types of gambling they engaged in during the prior month and the number of years they had played pachinko/pachislot at the normal cost as well as at half (or a quarter) of the normal rate. Participants were also asked to report the number of days they gambled during the prior month ("How many days did you gamble in the previous month?"), the total time spent ("How much time did you spend gambling in the previous month?"), and the total money spent on gambling ("How much money did you spend on gambling during the previous month? You need not give data about your income or expenditures related to gambling but only report money that you spent."). Moreover, participants were asked to report their present debts caused by gambling ("How much debt do you presently have that was caused by gambling?").

Japanese version of the Problem Gambling Severity Index-PGSI-J [3]. The PGSI [21->11] is a nine-item self-rated scale designed to assess gambling severity during the past year. The PGSI had a score of 027. Participants responded using a four-point Likert scale to indicate the extent to which they agreed with the values expressed in each item ( 0 = never; 1 = sometimes; 2 = most of the time; and $3=$ almost always). Higher scores indicated more severe gambling symptoms and were interpreted as follows: $8=$ nonproblematic; $1-2$ = low risk; $3-7$ = moderate risk; and 8 or more = problematic gambling (classification based on [21->11]). In this study, the total scale demonstrated high internal consistency $(a=0.95)$.

Japanese version of the Gambling Related Cognitions Scale (GRCS-J [22->12]). The GRCS [23->13] assesses gambling-related cognition. The GRCS-J is a 23-item questionnaire designed to measure gambling-related cognition. As with the original GRCS, participants responded using a seven-point Likert 
scale to indicate the extent to which they agreed with the values expressed in each item $(1=$ does not apply at all; 7 = fairly applicable). Higher scores indicated a higher number of cognitive distortions. The overall GRCS-J has good internal consistency $(a=0.94)$ and good convergent validity (correlation coefficient with SOGS-J: $r=0.61$ [22->12]). In this study, the total scale demonstrated high internal consistency $(a=0.97)$.

Japanese version of the Patient Health Questionnaire-9- PHQ-9-J [24->14]. The PHQ-9 [25->15] is a selfreported questionnaire for assessing depressive symptoms in the preceding two weeks. The questionnaire consists of nine items evaluated using a four-point Likert scale to indicate the extent to which participants agreed with the values expressed in each item ( $0=$ not at all, $3=$ nearly every day). Higher scores indicate more severe depressive symptoms. In an earlier study, this scale demonstrated good internal consistency $(a=0.93)$ and good convergent validity (correlation coefficient with the Kessler Psychological Distress Scale: $r=0.81)$ in a Japanese clinical population. In this study, the total scale demonstrated high internal consistency $(a=0.93)$.

Japanese version of the Sheehan Disability Scale- SDISS-J [26->16]. The SDISS [27->17] assesses disability across three domains-work, social life, and family life. As with the original SDISS, participants responded using an 11-point Likert scale to indicate the extent to which they agreed with the values expressed in each item ( $0=$ no problem at all; $10=$ substantial disability $)$ on the SDISS-J. Higher scores indicated more severe disability.

\section{Statistical Analysis}

Analyses were conducted using IBM SPSS Statistics version 26. Descriptive statistics were presented as means and standard deviations (SD) for each variable. To assess the effect of the harm reduction, a oneway ANCOVA was conducted to compare the effects of groups (normal-, half-, and quarter-pachi players) on dependent variables; namely, the number of days participants had gambled during the prior month, the total time and money spent on gambling, debts caused by gambling, gambling severity, total score of PGSI-J, cognitive distortion, total score of GRCS-J, and depressive symptoms (total score of PHQ-9-J, disability; SDISS-work, SDISS-Social life, and SDISS-Family life). Participants' sex, age, income, history of playing pachinko and pachislot, allowance, and other outcome variables were covariates. For all analyses, statistical significance was set at $p<0.05$.

\section{Results}

\section{Demographic characteristics}

We describe the demographic data of the study samples in Tables 1 and 2. Of the 305 participants, $85.57 \%(n=261)$ were male and $14.43 \%(n=44)$ were female. The participants' mean age was 51.11 years $(S D=12.87$; range $=20-80)$. Additionally, 33.11\% $(n=101)$ participants were normal-pachi players, $34.10 \%$ ( $n=104)$ were half-pachi players, and $32.79 \%(n=100)$ were quarter-pachi players. Furthermore, the mean score of the one-month allowance in entire sample was $\backslash 51477.38$ (SD = 65474.41); the mean 
one-month allowance for the groups was as follows - normal-pachi players: $\backslash 75178.22(S D=81350.77)$, half-pachi players: $\backslash 47467.31$ (SD=67311.31), and quarter-pachi players: $\backslash 31710.00(S D=27936.90)$. A one-way ANOVA was conducted with groups (normal-, half-, and quarter-pachi players) as independent variables and allowance as the dependent variable. The results showed a main effect of the groups $(F(2$, $302)=12.21, p=0.000)$. Bonferroni testing indicated that the allowance for normal-pachi players was significantly higher than that for half-pachi players $(p=0.006,95 \% \mathrm{Cl}=6460.44-48961.38)$ and quarterpachi players $(p=0.000,95 \% \mathrm{Cl}=22009.37-64927.06)$. There was no significant difference between the half- and quarter-pachi players $(p=0.228,95 \% \mathrm{Cl}=-5547.00-37061.62)$.

The mean years of the history of playing pachinko and pachislot in the full sample were 23.09 (SD= 13.72). They were $23.59(S D=12.55)$ for normal-pachi players, $27.88(S D=13.79)$ for half-pachi players, and $17.62(S D=12.91)$ for quarter-pachi players. A one-way ANOVA was conducted with the groups (normal-, half-, and quarter-pachi players) as independent variables and history of playing pachinko and pachislot as the dependent variable. The results showed a main effect of the groups $(F(2,302)=15.73$, $p=0.000$ ). Bonferroni testing indicated that there was no significant difference between the normal-and half-pachi players $(\mathrm{p}=0.058,95 \% \mathrm{Cl}=-8.70-0.11)$ in terms of history of playing pachinko and pachislot. The quarter-pachi players had a significantly lower mean than that of the normal-pachi players $(p=0.004$, $95 \% \mathrm{Cl}=1.51-10.41)$ and half-pachi players $(p=0.000,95 \% \mathrm{Cl}=5.84-14.68)$.

\section{Group differences on the dependent variable}

The means and SDs for each outcome variable are shown in Table 3.

A one-way ANCOVA was conducted to compare the amount of money spent on gambling between the three groups, controlling for the effects of sex, age, income, history of playing pachinko and pachislot, allowance, and other outcome variables. There was a significant difference in the amount of money spent on gambling between the groups $\left(F(2,288)=3.82, p=0.023\right.$, partial $\left.\eta^{2}=0.03\right)$. Post-hoc tests showed that there was a significant difference between normal- and quarter-pachi players $(p=0.02,95 \%$ $\mathrm{Cl}=2601.15-40652.19$ ). There was no significant difference in other outcome measures (the debt caused by gambling between groups: $F(2,288)=0.55, p=0.580$, partial $\eta^{2}=0.00$; the number of days participants gambled in the prior month between groups: $F(2,288)=0.31, p=0.73$, partial $\eta^{2}=0.00$; the time spent gambling between groups: $F(2,288)=1.86, p=0.158$, partial $\eta^{2}=0.01$; PGSI-J: $F(2,288)=0.27, p=0.76$, partial $\eta^{2}=0.00$; GRCS-J: $F(2,288)=1.27, p=0.28$, partial $\eta^{2}=0.01$; PHQ-9-J: $F(2,288)=0.21, p=0.81$, partial $\eta^{2}=0.00$; SDISS-work: $F(2,288)=2.07, p=0.127$, partial $\eta^{2}=0.01$; SDISS-Social life: $F(2,288)=$ $0.96, p=0.384$, partial $\eta^{2}=0.01$; SDISS-Family life: $F(2,288)=1.22, p=0.295$, partial $\left.\eta^{2}=0.01\right)$.

\section{Discussion}

This study was designed to examine the effect of lower investment types of pachinko/pachislot on gambling-related harms in adult gamblers. We sought to compare the differences in gambling-related harm between normal-, half-, and quarter-pachi players in terms of debt; number of days participants 
gambled during the prior month; total time and money spent on gambling; severity of gambling; gambling cognitive distortion; depressive symptoms; and degree of disability at work, in their family, and in their social lives. Our results demonstrated that the amount of money quarter-pachi players spent on gambling during the past month was lower than that spent by normal-pachi players. However, apart from the amount of money gamblers spent on gambling during the previous month, we did not find any significant differences in gambling-related harm among normal-, half-, and quarter-pachi players. These results suggest that low-investment pachinko/pachislot could serve to decrease only the amount of money gamblers spent on gambling. In addition, in the analyses of this study, the groups were the independent variable, and other variables (sex, age, income, money spent for entertainment and leisure, pachinko/pachislot playing history, and other outcome variables) were used as covariates to examine the effect on outcome measures. As a result, some control variables had a statistically significant influence on outcome measures in each analysis; therefore, we would like to discuss the support for gambling harm reduction comprehensively while considering these variables.

The results of this study showed that among gambling-related harms, the amount of money gamblers spent on gambling in the past month was lower among quarter-pachi players than among normal-pachi players. In other words, the quarter-pachi players engaged in gambling with a reduced risk of incurring financial harm from gambling. A previous study [6] demonstrated that gambling not only causes financial harm, but also leads to gambling behaviors and symptoms and affects mental health (for example, depressive symptoms) and interpersonal relationships (for example, social and family life). In the present study, we assumed that the harms experienced by gamblers who played low-investment pachinko (quarter- and half-pachi players) would be less severe than those experienced by normal-pachi players.

For gambling behaviors and symptoms, a previous study found that the more severe the gambling problem, the more time gamblers had to spend to acquire the fun and stimulation they desired [28->18] and the higher the irrational cognitive distortion [22->12]. Therefore, we assumed that low-investment pachinko/pachislot gamblers would have a lower level of gambling symptoms as well as a lower number of days, money, and total time spent on gambling. However, the results of this study found that there was no significant difference between the groups as per the PGSI-J, which measured the severity of gambling among groups, the number of days players had gambled in the prior month, the total time they had spent gambling, and gambling cognitive distortion. In other words, the fact that the participants in this study played pachinko/pachislot at a lower investment rate did not mean that they had a less severe gambling problem. In addition, participants in this study included people with a relatively long gambling history of 23.09 years; the years of playing pachinko/pachislot among all players were over 17 years. With a gambling history of over 17 years, participants' gambling would have already become a habit, and they would have to spend more time to acquire the enjoyment and stimulation obtained from gambling. This could have been the reason why there were no significant differences in depressive symptoms or degree of disability at work and in family and social life among the groups.

Based on the results of this study, we would like to discuss potential harm reduction approaches for lowinvestment pachinko players. The results of this study provide important insights because some control 
variables had a statistically significant influence on some outcome measures in each analysis. For example, when one variable, the amount of money spent on gambling, was included as a control variable in the analyses (outcome measures: debt of gambling, number of days gambled, degree of disability at work, and degree of disability in one's social life), it had positive effects on outcome measures. Although disordered gamblers have been found to gamble to solve financial difficulties [29->19], Table 4 shows that financial losses from gambling also affects work-related disability $(F(2,288)=4.000, p=0.046$, partial $\left.\eta^{2}=0.014\right)$. Therefore, the main analysis in this study found that reducing the amount of money gamblers spent on gambling could reduce some gambling-related harms.

Moreover, the results in this study indicate that the level of disability at work affects various outcomes for gamblers. Given that $90 \%$ of the participants in this study were employed (Table 1), the results of this study may have important implications for employed gamblers. While considering treatment interventions for those affected by gambling disorders, it is important to focus on helping individuals reduce their gambling behavior. On the other hand, based on the results of this study, it is also important to focus on the difficulties in gamblers' lives, especially their professional lives. In addition, depressive symptoms $\left(F(2,288)=4.514, p=0.034\right.$, partial $\left.\eta^{2}=0.015\right)$ and gambling severity $(F(2,288)=5.641, p=$ 0.018 , partial $\eta^{2}=0.019$ ) as well as financial loss were variables influencing gamblers' work-related disability (Table 4). Although these variables interact with each other [29], the results of this study indicate that financial loss and depressive symptoms caused by gambling can interfere with work, and in turn, work interference can exacerbate gambling-related harm. There are a number of supportive interventions that can be used to help alleviate work-related disability and increase work satisfaction, such as cognitive behavioral psychotherapy [30->20] and mindfulness [31->21]. Therefore, conducting these treatments may improve their prognosis.

\section{Limitations}

A potential limitation of this study is its cross-sectional design. Therefore, we cannot conclude whether the longitudinal use of low-investment pachinko/pachislot could reduce gambling harm. We have not been able to identify a causal relationship between harms faced by gamblers and low-investment pachinko/pachislot. Future studies must employ a longitudinal design to assess this causal relationship. Another limitation of the present study is the use of internet sampling. Given that most gamblers would not have received sufficient treatment or support to alleviate their gambling difficulties, the results of this study would be useful for people who have not received treatment. However, replication of the present study's results would lead to generalization of its findings not only in a non-clinical sample, but also for clinical assessment and treatment of disordered gamblers. Further, the fact that the sample for this study was skewed toward working, middle-aged males also limits the generalizability of the results. As a future study, it is important to conduct a similar survey with a larger sample or a different population.

\section{Conclusion}


While low-investment pachinko/pachislot is useful for gamblers who are currently experiencing financial harm, it has not also shown potential of being effective for gamblers facing mental health and lifestylerelated problems. For low-investment pachinko to be effective as a harm-reduction strategy in the context of treatment in Japan, it is important to conduct a thorough assessment of the gamblers' condition and carefully propose low-investment pachinko/pachislot as a less harmful alternative behavior depending on the outcome.

\section{Abbreviations}

Cl, confidence interval; PGSI-J, Japanese version of the Problem Gambling Severity Index; GRCS-J, Japanese version of the Gambling Related Cognitions Scale; PHQ-9-J, Japanese version of the Patient Health Questionnaire-9; SDISS-J, Japanese version of the Sheehan Disability Scale; SD, standard deviation; ANOVA, analysis of variance.

\section{Declarations}

\section{Ethics approval and consent to participate}

This study was reviewed by the Institutional Review Board of Hokusho University (2019-014) and completion of the internet survey by participants was considered to be informed consent. Participants were informed about study procedures and voluntary participation was emphasized.

\section{Consent for publication}

Not applicable.

\section{Availability of data and materials}

The datasets used and/or analyzed during the current study are available from the corresponding author on reasonable request.

\section{Competing interests}

$\mathrm{KY}$ received an honorarium from a casino operator.

\section{Funding}

This work was supported by Application Procedures for the Program for the International Dissemination of Research Results in Ritsumeikan University/JKA through its promotion funds from AUTORACE.

\section{Authors' contributions}

$\mathrm{KY}$ made substantial contributions to the conception; $\mathrm{KY}$ and $\mathrm{TI}$ designed the study and $\mathrm{KY}$ contributed to the acquisition of data. $\mathrm{KI}$ contribute to the analysis of data and $\mathrm{KY}$ and $\mathrm{KI}$ drafted the work and 
substantively revised it. All authors read and approved the final manuscript.

\section{Acknowledgements}

Not applicable.

\section{References}

1. Langham E, Throne H, Browne M, Donaldson P, Rose J, Rockloff M. Understanding gambling related harm: a proposed definition, conceptual framework, and taxonomy of harms. BMC Public Health. 2016; https://doi.org/10.1186/s12889-016-2747-0

2. Colado F, Griffiths MD. Problem gambling worldwide: An update and systematic review of empirical research (2000-2015). J Behav Addict. 2016; https://doi.org/10.1556/2006.5.2016.073

3. So R, Matsushita S, Kishimoto S, Furukawa TA. Development and validation of the Japanese version of the problem gambling severity index. Addict Behav. 2019; https://doi.org/10.1016/j.addbeh.2019.05.011.

4. Yokomitsu K, Sakai T, Irie T, Tayama J, Furukawa H, Himachi M et al. Gambling symptoms, behaviors, and cognitive distortions in Japanese university students. Subst Abuse Treat Prev Policy. 2019; https://doi.org/10.1186/s13011-019-0230-5

5. Shoun A, Sakamoto A, Horiuchi Y, Akiyama K, Ishida H, Shinohara K et al. Pachinko/pachislot playing participation in Japan: Results from a national survey. J Gambl Issues.

2020; https://doi.org/10.4309/jgi.2021.46.8

6. Langham E, Thorne H, Browne M, Donaldson P, Rose J, Rockloff M. Understanding gambling related harm: A proposed definition, conceptual framework, and taxonomy of harms. BMC Public Health. 2016; https://doi.org/10.1186/s12889-016-2747-0

7. Harris A, Griffiths MD. A critical review of the harm-minimisation tools available for electronic gambling. J Gambl Stud. 2017; https://doi.org/10.1007/s10899-016-9624-8

8. McMahon N, Thomson K, Kaner E, Bambra C. Effects of prevention and harm reduction interventions on gambling behaviours and gambling related harm: An umbrella review. Addict Behav. 2019; https://doi.org/10.1016/j.addbeh.2018.11.048

9. Tanner J, Drawson AS, Mushquash CJ, Mushquash AR, Mazmanian D. Harm reduction in gambling: A systematic review of industry strategies. Addict Res Theory. 2017; https://doi.org/10.1080/16066359.2017.1310204

10. Sharpe L, Walker M, Coughlan MJ, Enersen K, Blaszczynski A. Structural changes to electronic gaming machines as effective harm minimization strategies for non-problem and problem gamblers. J Gambl Stud. 2005; https://doi.org/10.1007/s10899-005-5560-8

11. Ferris JA, Wynne HJ. The Canadian problem gambling index. Ottawa, ON: Canadian Centre on Substance Abuse. 2001. 
12. Yokomitsu K, Takahashi T, Kanazawa J, Sakano Y. Development and validation of the Japanese version of the Gambling Related Cognitions Scale (GRCS-J). Asian J Gambl Issues Public Health. 2015; https://doi.org/10.1186/s40405-015-0006-4

13. Oei TPS, Lin J, Raylu N. Validation of the Chinese version of the Gambling Related Cognitions Scale (GRCS-C). J Gambl Stud. 2007; https://doi.org/10.1007/s10899-006-9040-6

14. Ito, M, Doi S, Takebayashi Y, Muramatsu K, Horikoshi M. Factorial validity and invariance of the Patient Health Questionnaire (PHQ)-9 among clinical and non-clinical populations. PLOS ONE. 2018; https://doi.org/10.1371/journal.pone.0199235

15. Kroenke K, Spitzer RL, Williams JBW. The PHQ-9: Validity of a brief depression severity measure. J Gen Intern Med. 2001; https://doi.org/10.1046/j.1525-1497.2001.016009606.x

16. Yoshida T, Ohtsubo T, Tsuchida H. Study of reliability and validity of a Japanese version of Sheehan Disability Scale (SDISS). Jpn J Clin Psychopharmacol. 2004;7:1645-53. [Japanese]

17. Sheehan DV, Harnett-Sheehan K, Raj BA. The measurement of disability. Int Clin Psychopharmacol. 1996; https://doi.org/10.1097/00004850-199606003-00015

18. Tsurumi K, Kawada R, Yokoyama N, Sugihara G, Sawamoto N, Aso T et al. Insular activation during reward anticipation reflects duration of illness in abstinent pathological gamblers. Front Psychol. 2014; https://doi.org/10.3389/fpsyg.2014.01013

19. Mathieu S, Barrault S, Brunault P, Varescon I. Gambling motives: Do they explain cognitive distortions in male poker gamblers? J Gambl Stud. 2018; https://doi.org/10.1007/s10899-017-9700-8

20. Wang PS, Simon GE, Avorn J, Azocar F, Ludman EJ, McCulloch J et al. Telephone screening, outreach, and care management for depressed workers and impact on clinical and work productivity outcomes: A randomized controlled trial. JAMA. 2007; https://doi.org/10.1001/jama.298.12.1401

21. Coo C, Salanova M. Mindfulness can make you happy-and-productive: A mindfulness controlled trial and its effects on happiness, work engagement and performance. J Happiness Stud. 2018; https://doi.org/10.1007/s10902-017-9892-8

\section{Tables}




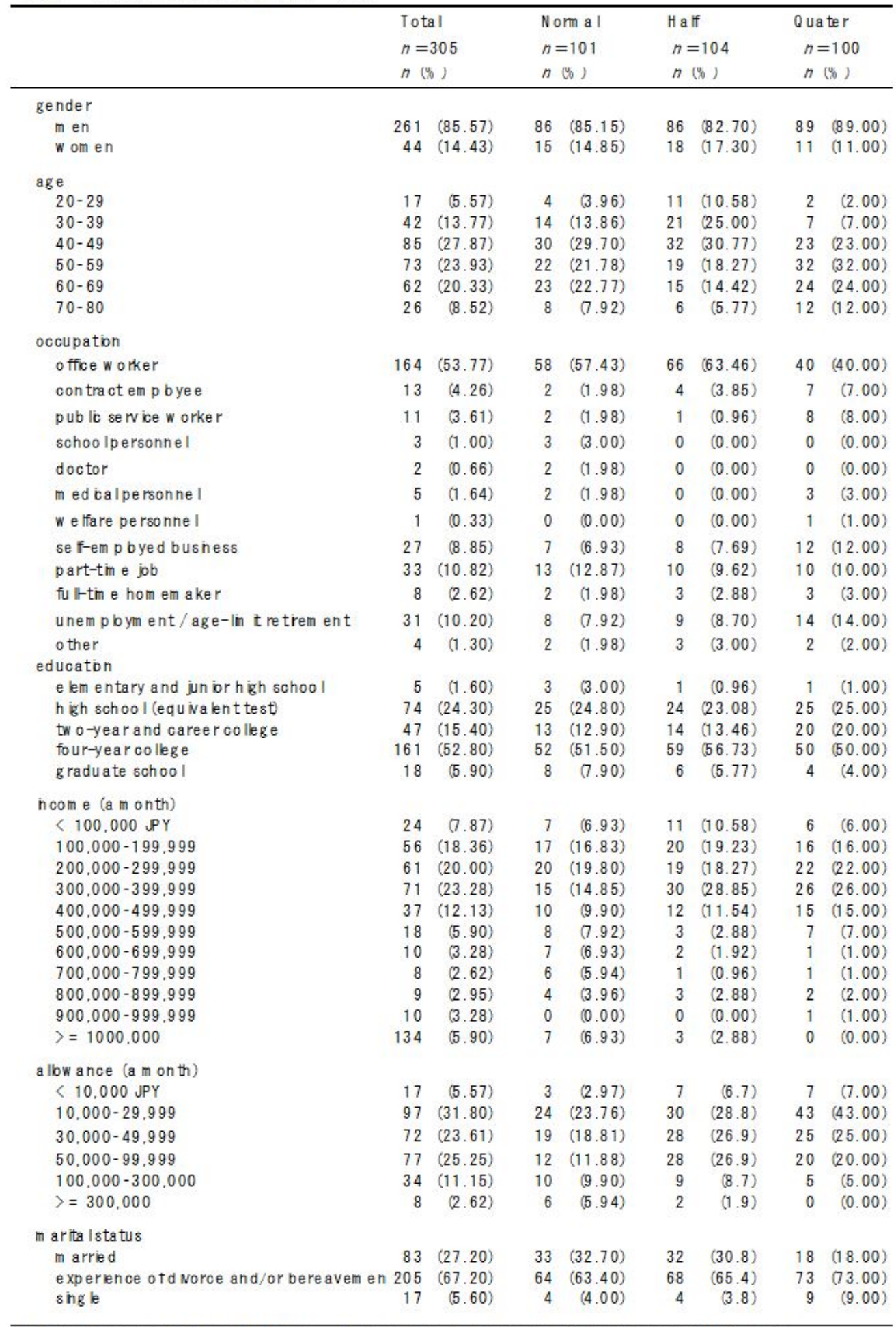

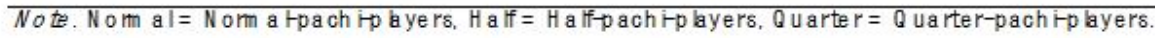




$\begin{array}{llll}\text { Total } & \text { Nom a I } & \text { H alf } & \text { Quarter } \\ n=305 & n=101 & n=104 & n=100 \\ n(\%) & n(\%) & n(W) & n(\%)\end{array}$

\begin{tabular}{|c|c|c|c|c|c|c|c|c|}
\hline$<5$ year & 28 & $(9.18)$ & 5 & $(4.95)$ & 3 & $(2.88)$ & 20 & $(20.00)$ \\
\hline $5-9.9$ & 30 & $(9.84)$ & 9 & $(8.91)$ & 5 & $(4.81)$ & 16 & $(16.00)$ \\
\hline $10-19.9$ & 51 & $(16.72)$ & 18 & $(17.82)$ & 18 & $(17.31)$ & 15 & $(15.00)$ \\
\hline $20-29.9$ & 80 & $(26.23)$ & 25 & $(24.75)$ & 30 & $(28.85)$ & 25 & $(25.00)$ \\
\hline $30-39.9$ & 61 & $(20.00)$ & 29 & $(28.71)$ & 18 & $(17.31)$ & 14 & $(14.00)$ \\
\hline $40-49.9$ & 44 & $(14.43)$ & 12 & $(11.88)$ & 15 & $(14.42)$ & 10 & $(10.00)$ \\
\hline $50-59.9$ & 11 & $(3.61)$ & 3 & $(2.97)$ & 8 & $(7.69)$ & 0 & $(0.00)$ \\
\hline$>=60$ over & 0 & $(0.00)$ & 0 & $(0.00)$ & 0 & $(0.00)$ & 0 & $(0.00)$ \\
\hline \multicolumn{9}{|l|}{ Types of gam bling } \\
\hline sbtm ach nes (notonline) & 232 & $(76.07)$ & 84 & $(83.17)$ & 97 & $(93.27)$ & 51 & $(51.00)$ \\
\hline pach inko & 280 & $(91.80)$ & 92 & $(91.09)$ & 96 & $(92.31)$ & 92 & $(92.00)$ \\
\hline m ahjong & 98 & (32.13) & 37 & $(36.63)$ & 42 & $(40.38)$ & 19 & $(19.00)$ \\
\hline bttery (b to, num bers, etc.) & 229 & $(75.08)$ & 82 & $(81.19)$ & 82 & $(78.85)$ & 65 & $(65.00)$ \\
\hline casino (notonline) & 54 & $(17.70)$ & 22 & $(21.78)$ & 23 & $(22.12)$ & 9 & $(9.00)$ \\
\hline horse races & 163 & $(53.44)$ & 61 & $(60.40)$ & 69 & $(66.35)$ & 33 & $(0.00)$ \\
\hline to to (sportbetting) & 139 & $(45.57)$ & 54 & $(53.47)$ & 59 & $(56.73)$ & 26 & $(26.00)$ \\
\hline ke irn (b icycle races) & 94 & $(30.82)$ & 30 & $(29.70)$ & 49 & $(47.12)$ & 15 & $(15.00)$ \\
\hline motorboat races & 101 & (33.11) & 34 & $(33.66)$ & 50 & $(48.08)$ & 17 & $(17.00)$ \\
\hline others & 0 & $(0.00)$ & 0 & $(0.00)$ & 0 & $(0.00)$ & 0 & $(0.00)$ \\
\hline
\end{tabular}

Note. As tor the types of gam bIng, those who had done th once durng the prorm onth we re counted.

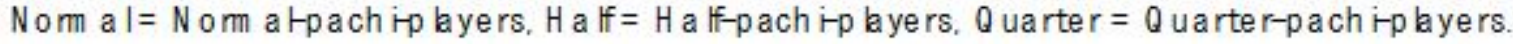

Tab le 3 Descriptive sta tistics about variables $(n=305)$

\begin{tabular}{|c|c|c|c|c|c|c|c|c|}
\hline & \multicolumn{2}{|c|}{$\begin{array}{r}\text { Total } \\
n=305\end{array}$} & \multicolumn{2}{|c|}{$\begin{array}{l}\text { Noim a l } \\
n=101\end{array}$} & \multicolumn{2}{|c|}{$\begin{array}{c}\mathrm{H} \text { alf } \\
n=104\end{array}$} & \multicolumn{2}{|c|}{$\begin{array}{l}\text { Quarter } \\
n=100\end{array}$} \\
\hline & Wean & SD & Mean & SD & Wean & SD & Mean & $S D$ \\
\hline Am ountorm oney spenton gam b ing & $3 Z \angle U 0.10$ & $0 / 400.01$ & $00 \angle 41.08$ & $y 0 / 11 . y 1$ & $2 / 0 s y .41$ & $08403.1 y$ & I SZOO.UU & 13001.80 \\
\hline The debts caused by gam b ling at present & 88891.15 & 549850.72 & 170792.08 & 868886.28 & 74584.62 & 359193.06 & 21050.00 & 140910.27 \\
\hline $\begin{array}{l}\text { I he num berotdays partic pants had gam bled } \\
\text { durng the priorm onth }\end{array}$ & 5.67 & 5.91 & 6.51 & 6.64 & 5.23 & 5.60 & 5.27 & 5.39 \\
\hline The totaltme spentongam b ling & 15.17 & 23.76 & 17.84 & 24.06 & 11.62 & 16.57 & 16.16 & 29.01 \\
\hline PGSI & 13.73 & 6.10 & 14.10 & 6.48 & 14.52 & 6.33 & 12.55 & 5.28 \\
\hline GRCS & 76.27 & 28.53 & 78.58 & 29.73 & 80.00 & 28.66 & 70.04 & 26.33 \\
\hline $\mathrm{PHQ}-9$ & 14.88 & 5.80 & 14.81 & 5.70 & 15.31 & 5.87 & 14.51 & 5.86 \\
\hline SD ISS-W ork & 3.73 & 2.84 & 3.50 & 2.86 & 4.28 & 2.92 & 3.39 & 2.68 \\
\hline SD ISS-Soc ial life & 3.64 & 2.78 & 3.53 & 2.89 & 4.12 & 2.75 & 3.25 & 2.64 \\
\hline SD ISS-Fam ily life & 3.62 & 2.69 & 3.52 & 2.86 & 3.97 & 2.56 & 3.35 & 2.66 \\
\hline
\end{tabular}

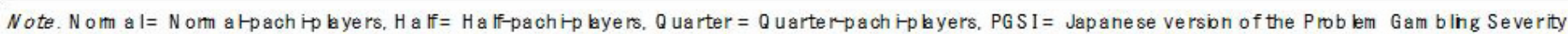

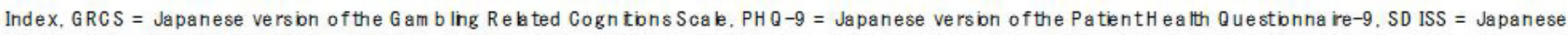
version of the Sheehan D isab ilty Scak. 
Tota $10 \mathrm{~N}=305$

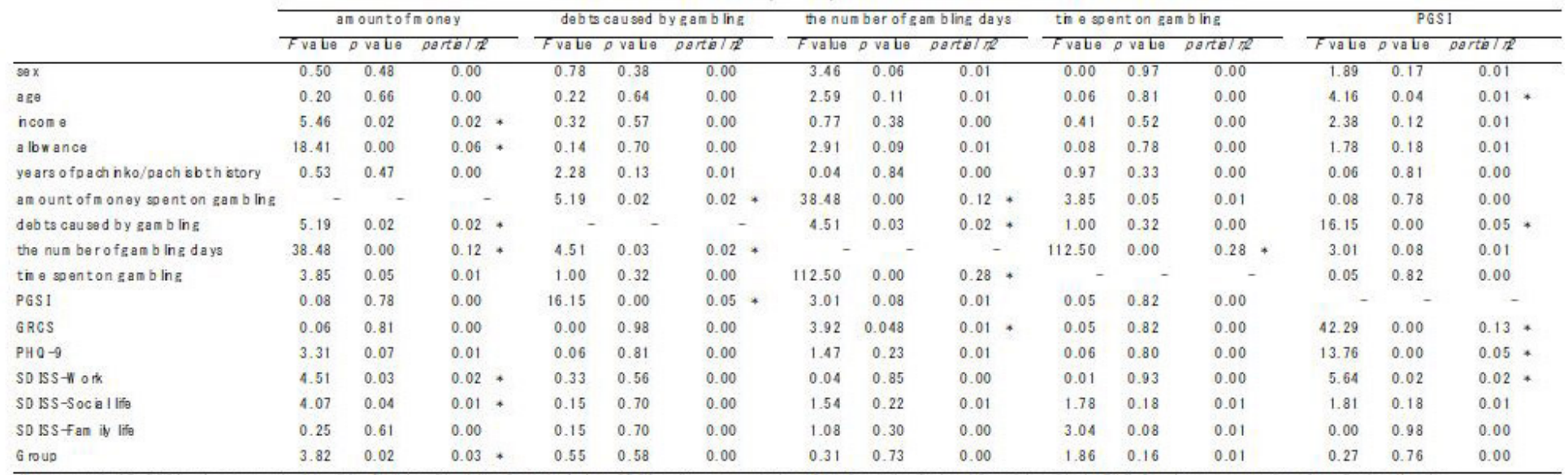

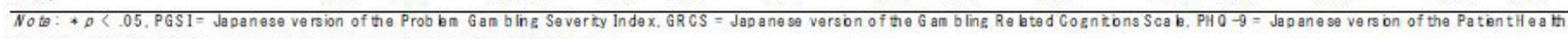

Ouestonna re-9. SD ISS = Japanese verson of the Sheahan D sability Scala.

Tabb 4 The n pactofothervarablas on the earch outron e (ANCOVA)

\begin{tabular}{|c|c|c|c|c|c|c|c|c|c|c|c|c|c|c|c|c|}
\hline & \multicolumn{3}{|c|}{ GRCS } & \multicolumn{3}{|c|}{ PHO } & \multicolumn{4}{|c|}{ Soiss-k ork } & \multicolumn{3}{|c|}{ SOISS-SOcell洒 } & \multicolumn{3}{|c|}{ 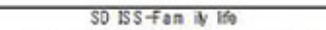 } \\
\hline & FVato & O valuo & portio/ द2 & Fvato & D Vato & Dortolf? & F valuo & OVALO & Dertel/z & & FVaLO & DVELO & Dortelth & FVaLO & DVELO & $00 \pi 0 / \pi 2$ \\
\hline sex & 1.74 & 0.19 & 0.01 & 2.16 & 0.14 & 0.01 & 0.08 & 0.77 & 0.00 & & 0.60 & 0.44 & 0.00 & 0.88 & 0.35 & 0.00 \\
\hline age & 2.17 & 0.14 & 0.01 & 0.10 & 0.76 & 0.00 & 0.82 & 0.37 & 0.00 & & 0.66 & 0.42 & 0.00 & 1.56 & 0.21 & 0.01 \\
\hline noone $\theta$ & 0.44 & 0.51 & 0.00 & 2.87 & 0.09 & 0.01 & 0.35 & 0.55 & 0.00 & & 0.11 & 0.74 & 0.00 & 0.17 & 0.68 & 0.00 \\
\hline a lbw ance & 1.69 & 0.19 & 0.01 & 0.00 & 1.00 & 0.00 & 5.13 & 0.02 & 0.02 & & 6.53 & 0.01 & 0.02 & 0.06 & 0.81 & 0.00 \\
\hline years of pach inko/pach ib b th sto ry & 1.64 & 0.20 & 0.01 & 2.52 & 0.11 & 0.01 & 0.12 & 0.73 & 0.00 & & 0.07 & 0.78 & 0.00 & 1.98 & 0.16 & 0.01 \\
\hline an ount of $n$ oney soenton gan b ing & 0.06 & 0.81 & 0.00 & 3.31 & 0.07 & 0.01 & 4.51 & 0.03 & $0.02 *$ & - & 4.07 & 0.04 & 0.01 & 0.25 & 0.61 & 0.00 \\
\hline dobta causod by gan bing & 0.00 & 0.98 & 0.00 & 0.06 & 0.81 & 0.00 & 0.33 & 0.56 & 0.00 & & 0.15 & 0.70 & 0.00 & 0.15 & 0.70 & 0.00 \\
\hline the nun ber of gan bling days & 3.92 & 0.049 & 0.01 * & 1.47 & 0.23 & 0.01 & 0.04 & 0.85 & 0.00 & & 1.54 & 0.22 & 0.01 & 1.08 & 0.30 & 0.00 \\
\hline the spent on $g a n$ b ing & 0.05 & 0.82 & 0.00 & 0.06 & 0.80 & 0.00 & 0.01 & 0.93 & 0.00 & & 1.78 & 0.18 & 0.01 & 3.04 & 0.08 & 0.01 \\
\hline PGS1 & 42.29 & 0.00 & 0.13 & 13.76 & 0.00 & $0.05 *$ & 5.64 & 0.02 & $0.02 *$ & * & 1.81 & 0.18 & 0.01 & 0.00 & 0.98 & 0.00 \\
\hline GRCS & - & - & - & 0.32 & 0.57 & 0.00 & 1.05 & 0.31 & 0.00 & & 0.31 & 0.58 & 0.00 & 2.25 & 0.13 & 0.01 \\
\hline PHO 0 -9 & 0.32 & 0.57 & 0.00 & - & - & - & 4.00 & 0.046 & $0.01 *$ & * & 0.91 & 0.34 & 0.00 & 0.58 & 0.45 & 0.00 \\
\hline So ISS-K ork & 1.05 & 0.31 & 0.00 & 4.00 & 0.046 & $0.01 *$ & - & - & - & & 254.20 & 0.00 & 0.47 & 37.13 & 0.00 & $0.11 *$ \\
\hline SO ISS-SOciallis & 0.31 & 0.58 & 0.00 & 0.91 & 0.34 & 0.00 & 254.20 & 0.00 & 0.47 . & - & - & - & - & 45.35 & 0.00 & 0.14. \\
\hline SO ISS-Fan in If & 2.25 & 0.13 & 0.01 & 0.58 & 0.45 & 0.00 & 37.13 & 0.00 & 0.11. & - & 45.35 & 0.00 & 0.14 & • & - & - \\
\hline Group & 1.27 & 0.28 & 0.01 & 0.21 & 0.81 & 0.00 & 2.07 & 0.13 & 0.01 & & 0.96 & 0.38 & 0.01 & 1.22 & 0.30 & 0.01 \\
\hline
\end{tabular}

Figures

\section{Image not available with this version}

Figure 1 